\title{
Improved Synthesis of N-Substituted Quinolinimides Using Microwave Irradiation
}

\author{
M. M. Blanco, I. A. Perillo, and C. B. Schapira \\ Departamento de Química Orgánica, Facultad de Farmacia y Bioquímica, UBA, Junín 956 (1113), \\ Buenos Aires, Argentina \\ E-mail: iperillo@ffyb.uba.ar
}

\begin{abstract}
The synthesis of several quinolinimidoacetic acid derivatives (I) by two different routes, starting from quinolinic anhydride or quinolinimide, is described. In all cases better yields and decreased reaction times were achieved employing microwave irradiation as an alternative source of energy.
\end{abstract}

\section{Introduction}

A number of 1,6- and 1,7-naphthyridines were synthesized [1] by expansion reactions induced by alkoxides of quinolinimidoacetic acid derivatives (I). These compounds were obtained with low yields after several hours using conventional heating methods.


I<smiles>[X]C(=O)C(NC(=O)[O-])=C(O)c1cccnc1Cl</smiles>

Here we present the improved results obtained when reactions have been carried out under microwave irradiation.

\section{Experimental}

Ordinary kitchen microwave oven was used to perform the reactions.

\section{Results and discussion}

Compounds I were obtained by two ways:

a) By heating quinolinic anhydride (II) and aminoacetic acid derivatives. The yields are low owing to decarboxylation reactions of the intermediate quinolinic acid monoamides. 


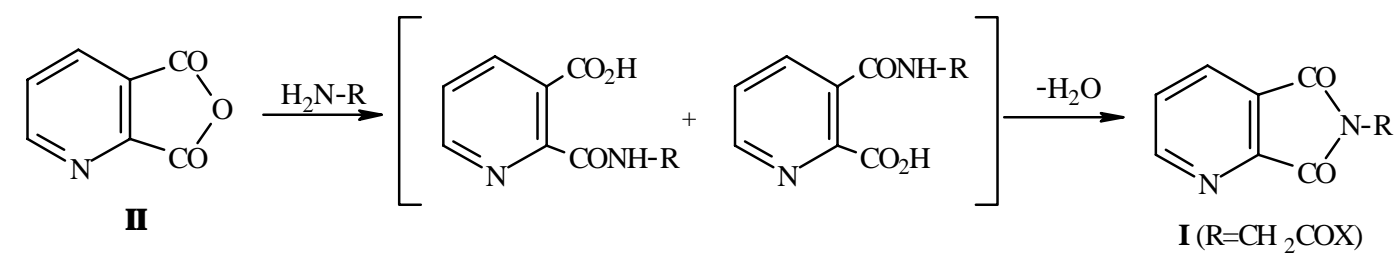

When reactions have been carried out with microwave heating remarkable rate enhancements and dramatic savings in reaction times were observed.

This method was extended and optimized for synthesis of N-substituted alkyl, aryl or heterocyclic quinolinimides as well as for N,N-disubstituted 2-carbamoyl-nicotinic and 3-carbamoylpicolinic acids.

b) Compounds I were also obtained by $\mathrm{N}$-alkylation of quinolinimide III, which was prepared with high yields from quinolinic acid and aqueous ammonia with microwave heating $(7 \mathrm{~min} ., 500 \mathrm{w})$.

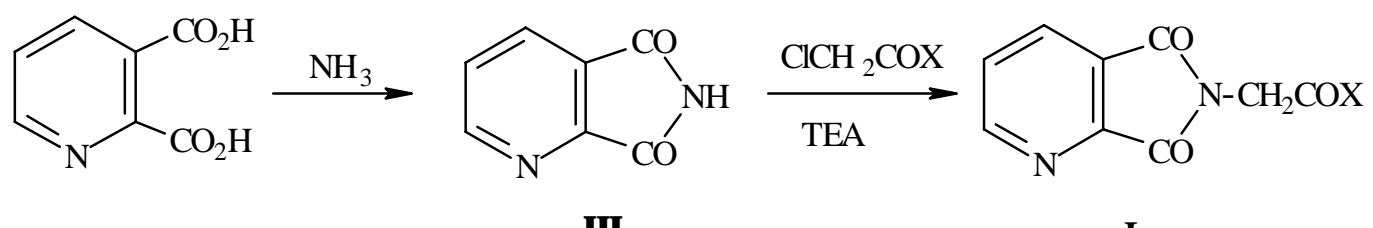

III

The best results in $\mathrm{N}$-alkylation reactions were achieved in DMF using $\mathrm{Et}_{3} \mathrm{~N}$ as base.

\section{References}

1. Mercedes Blanco, M.; Gabriela Lorenzo; Isabel A. Perillo; Celia B. Schapira. J. Heterocyclic Chem. 1996, 33, 1. 